\section{Терелянский П.В.}

д-р экон. наук, канд. техн. наук, ФГБОУ ВО «Государственный университет управления», г. Москва

e-mail: tereliansky@mail.ru

\section{Terelyanskiy P.V.}

Doctor of Economic Sciences, Candidate of Technical Sciences, State University of Management Moscow

e-mail: tereliansky@mail.ru

\section{Процесс трансформации вещной экспортно-ориентированной экономики России в цифровую}

\begin{abstract}
Аннотация
Исследованы данные статистики по объему реализации продукции четырехсот ведущих российских компаний, консолидированные медиахолдингом «Эксперт» в преддверии принятия распоряжения Правительства Российской Федерации от 28 июля 2017 г. № 1632-р об утверждении программы «Цифровая экономика Российской Федерации». Основной целью программы является процесс трансформации вещной экспортно-ориентированной экономики России в цифровую. Процесс такой транссоормации предполагает, что валовой внутренний продукт должен формироваться за счет производства в основном «виртуальных» товаров. Таким образом, цифровизация экономики подразумевает переориентацию производительных сил общества с производства и преобразования материальных объектов на сферу производства и преобразования числовых массивов, которые хранятся, обрабатываются и передаются посредством современной информационно-технологической инфраструктуры. Насколько готова экономика и промышленность Российской Федерации к такой трансформации, каково базовое состояние общественных и производительных сил поддержать процесс транссормации вещной экспортно-ориентированной экономики в цифровую, можно косвенно оценить по объему реализации ведущих отечественных компаний. Подразумевается, что чем выше доля объема реализации информационно-технологически ориентированных производств и компаний в совокупном объеме ведущих отечественных компаний, тем выше степень транссоормации ресурсно-ориентированной и материалоемкой экономики в экономику цифровую. Если считать, что банковские услуги составляют основную часть современной цифровой экономики наряду с информационно-технологическими компаниями и компаниями по передаче мобильных данных, то их доля по сравнению с ресурсодобывающими компаниями первой десятки ведущих российских компаний составит более трети (34 \%) объема реализации, что позволяет говорить об уверенном процессе цифровой трансформации российской экономики.
\end{abstract}

\section{Ключевые слова:}

цифровая экономика, цифровая трансформация, статистические исследования, объем реализации, макроэкономические агенты, валовой внутренний продукт.

\section{The process of transformation of export-oriented real economy of Russia in the digital economy}

\begin{abstract}
The subject of the article's study are the statistics on the volume of sales of four hundred leading Russian companies, consolidated by media holding «Expert», on the eve of the adoption of the order of the Russian Federation Government (July 28, 2017 № 1632-p) on the approval of the national program «Digital economy of the Russian Federation». The main program's objective is the process transformation of real export-oriented Russia economy into a digital economy. The transformation process implies gross domestic product should be generated by the production of mainly «virtual» goods. Thus, the economy digitalization implies the reorientation the productive forces of society from the production and transformation of material objects to the production and transformation of numerical arrays sphere that are stored, processed and transmitted through modern IT-infrastructure. The extent to which the economy and industry of the Russian Federation are ready for such a transformation, the state of social and productive forces to support the process of the real export-oriented economy of Russia transformation into a digital one, can be indirectly estimated by the sales volume of leading Russian companies. It is assumed that the higher the share of IT-oriented industries and companies in the total volume of leading domestic companies, the higher the degree of transformation of resourceoriented and material-intensive economy into digital economy. If we assume that banking services constitute the main part of the modern digital economy along with IT companies and mobile data transmission companies, their share in comparison with the resource companies of the top ten leading Russian companies will be more than a third percents of the sales volume. That situation makes it possible to talk about a confident process of digital transformation of the Russian economy.
\end{abstract}

\section{Keywords:}

digital economy, digital transformation, statistical research, sales volume, macroeconomic agents, gross domestic product.

(C) The Author(s), 2018 This is an open access article under the CC BY 4.0 license (http://creativecommons.org/licenses/by/4.0/) 
Распоряжением правительства № 1632-р от 28го июля 2017 г. была утверждена программа «Цифровая экономика Российской Федерации». Программа призвана осуществляться в соответствии с «целями, задачами, направлениями, объемами и сроками реализации основных мер государственной политики Российской Федерации (далее - РФ) по созданию необходимых условий для развития цифровой экономики РФ, в которой данные в цифровой форме являются ключевым фактором производства во всех сферах социально-экономической деятельности» [1]. Программа подготовлена для реализации Стратегии развития информационного общества в РФ на 2017-2030 гг., утвержденной Указом Президента РФ от 9 мая 2017 г. № 203 [2].

Основной целью программы является процесс трансформации вещной экспортно-ориентированной экономики России в цифровую [6; 7]. Процесс такой трансформации предполагает, что валовой внутренний продукт должен формироваться за счет производства в основном «виртуальных» товаров, сущностью которых будет: во-первых, низкое потребление невосполняемых материальных ресурсов; во-вторых, низкое потребление энергии; в-третьих, полное отсутствие износа товара во время эксплуатации; в-четвертых, и это главное свойство таких товаров, способность неограниченного копирования, практически без потребления материальных ресурсов и энергии.

Ярким примером таких товаров могут быть виртуальные товары в компьютерных играх - затраты материальных и энергетических ресурсов для создания путем копирования какого-нибудь меча для главного героя или пушки для виртуального танка будут равны стоимости хранения нескольких байт информации и нескольких милливатт электроэнергии. При этом цена такого электронного товара может достигать существенных сумм вполне реальных денег. Стоимость создания первой единицы такого виртуального товара складывается в основном из стоимости человеко-часа программиста, различных роялти, амортизации информационно-технологического (далее - ИТ) оборудования, объема потребленной электроэнергии ИТ-оборудованием, аренды офисных помещений и прочих весьма незначительных затрат. Исключение составляет, пожалуй, только продукция кино-, теле- и радио-компаний, где основные затраты составляют гонорары исполнителям и руководителям творческих процессов. В «доцифровую» эпоху огромные материальные средства тратились на создание декораций и еще большие на печать фильмокопий на кинопленке. Количество фильмокопий теоретически было ограничено возможностями кинокопировальных фабрик, сейчас количество фильмокопий ограничивает только лицензия на прокат. Так же исключением является и афера с производством биткоиноподобных криптовалют, где основные затраты составляет покупка и амортизация оборудования, а также процесс электрического нагрева полупроводниковых элементов видеоплат за счет грандиозного объема самодостаточных (нужных алгоритму только для работы самого этого алгоритма) вычислений [8].

Таким образом, цифровизация экономики подразумевает переориентацию производительных сил общества с производства и преобразования материальных объектов на сферу производства и преобразования числовых массивов, которые хранятся, обрабатываются и передаются посредством современной ИТ-инфраструктуры. Насколько готова экономика и промышленность РФ к такой трансформации, каково базовое состояние общественных и производительных сил, существует ли возможность у макроэкономических агентов поддержать процесс трансформации вещной экспортноориентированной экономики России в цифровую, можно косвенно оценить по объему реализации ведущих отечественных компаний $[9 ; 10]$. Подразумевается, что чем выше доля объема реализации ИТ-ориентированных производств и компаний в совокупном объеме ведущих отечественных компаний, тем выше степень трансформации ресурснооринетированной и материалоемкой экономики в экономику цифровую.

По данным статистики, собранным в 2017 г. медиахолдингом «Эксперт», среди 400 ведущих российских компаний по критерию «Объем реализации» в первую десятку вошли: на первых 3 местах, а также 9-е место рейтинга нефте- и газодобывающие компании, на 4-м и 6-м местах предприятия финансовый сферы, на 5-м месте естественная транспортная монополия РЖД, на 7-м и 8-м местах крупнейшие продуктовые ритейлеры, на 10-м месте оператор энергетических сетей (табл. 1) [3].

Данное распределение хорошо иллюстрирует функционирование классической энергоориентированной «вещной» экономики. Добываются ресурсы (ПАО «Газпром» (далее - Газпром), НК «Лукойл», НК «Роснефть», «Сургутнефтегаз»), обеспечивается транспортировка ресурсов (ОАО «РЖД»), для чего привлекается энергообеспечение (ПАО «Российские сети»), осуществляется розничный и мелкооптовый ритейл товаров народного потребления (розничная сеть «Магнит», X5 Retail Group) и все это сопровождается проведением необходимых финансовых операций (Сбербанк России, группа ВТБ). 
Первая десятка отечественных компаний по объему реализации продукции

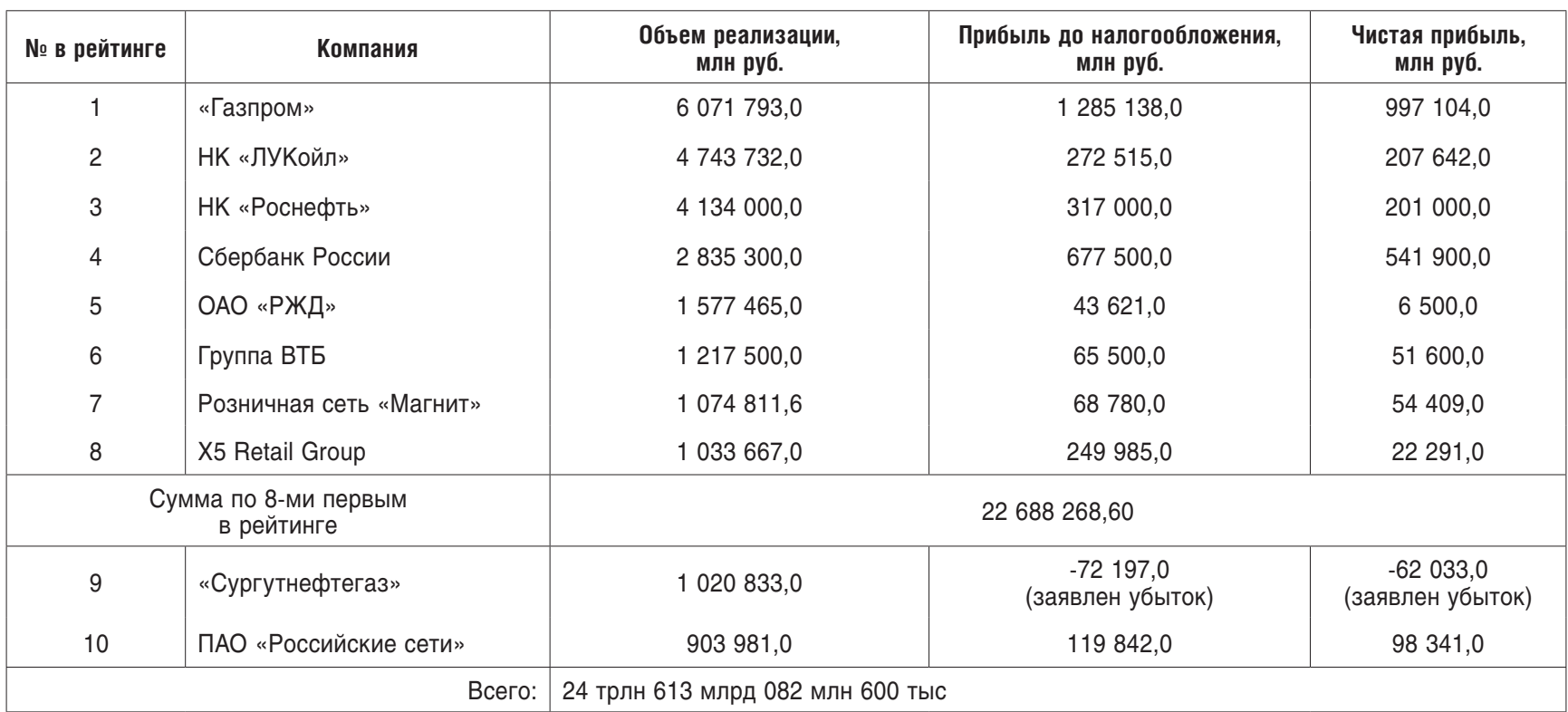

Источник: [3]

И только на 89-м месте впервые появляется ИТкомпания: «Национальная компьютерная корпорация», объединяющая более 30 офисов на территории РФ, собственный завод по производству компьютерной техники, более 300 авторизованных сервисных центров во всех субъектах РФ, более 9 тыс. партнеров (компьютерных компаний), более 250 партнерских контрактов с крупнейшими мировыми производителями, с объемом реализации продукции 161 млн 271 тыс. руб. (по данным сайта компании), что составляет чуть более $3 \%$ от объема реализации ведущего представителя российского бизнеса Газпрома (табл. 2) [5].
Далее, со значительным отрывом, на 125-м месте во второй сотне рейтинга идет группа компаний ИТ-компаний «ЛАНИТ» с объемом реализации в 99 млрд 87 млн руб.

В конце третьей сотни рейтинга $(251,265$ и 272е место) следуют ГК «Техносерв», Softline, Mail.Ru group, ГK Verysell.

Всего же 8 отечественных ИТ-компаний, вошедших в 400-местный рейтинг ведущих компаний (Национальная компьютерная корпорация, ГК ЛАНИТ, «Яндекс», ГК «Техносерв», Softline, Mail.Ru group, ГК Verysell, российское представительство Google), обеспечили 504 млрд 605 млн 900 тыс. руб.,

Таблица 2

Компании, вошедшие в сегмент «Информационные технологии»

\begin{tabular}{|c|c|c|c|c|}
\hline № в рейтинге & Компания & $\begin{array}{c}\text { Объем реализации, } \\
\text { млн руб. }\end{array}$ & $\begin{array}{c}\text { Прибыль до налогообложения, } \\
\text { млн руб. }\end{array}$ & $\begin{array}{c}\text { Чистая прибыль, } \\
\text { млн руб. }\end{array}$ \\
\hline 89 & $\begin{array}{l}\text { Национальная компьютерная } \\
\text { корпорация }\end{array}$ & 139411,3 & нет данных & нет данных \\
\hline 125 & ГК ЛАНИТ & 99087,4 & нет данных & нет данных \\
\hline 165 & «Яндекс» & 75900,0 & нет данных & нет данных \\
\hline 251 & ГК «Техносерв» & 44442,6 & нет данных & нет данных \\
\hline 265 & Softline & 41881,6 & нет данных & нет данных \\
\hline 272 & Mail.Ru group & 40001,0 & 12669,0 & 11831,0 \\
\hline 318 & 「K Verysell & 33965,0 & 33,0 & 20,0 \\
\hline 348 & Google & 29917,0 & 4026,0 & 3155,0 \\
\hline & Всего: & \multicolumn{3}{|c|}{504 млрд 605 млн 900 тыс. руб. } \\
\hline
\end{tabular}


Компании, вошедшие в сегмент «Телекоммуникации и связь»

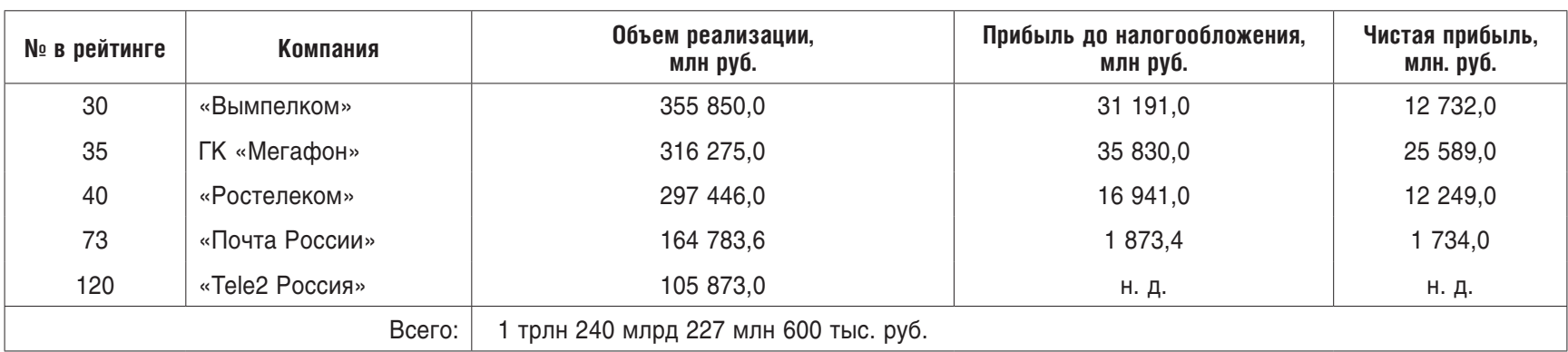

Источник: [3]

что составляет $8,3 \%$ от объемов реализации всего лишь одного ведущего ресурсодобывающего гиганта Газпром.

Если же сравнить объем реализации восьми первых в рейтинге российских компаний, являющихся естественными монополиями, ресурсодобывающими компаниями и ритейлерами, то есть компаниями не производящими высокотехнологичного цифрового продукта, за исключением, конечно, продуктов обеспечивающих банковские транзакции, то доля в объеме реализации ИТ-компаний составит только чуть более $2,2 \%$.

В первой сотне рейтинга на $30,35,40,73-\mathrm{M}$, а также и 120-м местах находятся компании предоставляющие услуги связи с общим объемом реализации 1 трлн 240 млрд 227 млн 600 тыс. руб. (табл. 3).

Если рассматривать услуги связи, как неотъемлемую часть информационно-коммуникационных технологий (всего 13 компаний из табл. 2 и табл. 3), а по прогнозу Ericsson Mobility Report к 2020 г. 85 \% всех мобильных подключений в 2020 г. составят подключения к сетям МШПД (мобильный широкополосный доступ, мобильный Интернет, LTE), то доля объема реализации ИТ- и цифровых услуг на сегодняшний момент составляет (1 трлн 745 мл рд 205 млн 900 тыс. руб.), чуть более 7 \% от объема прибыли 10-ти ведущих отечественных компаний из рассматриваемого рейтинга [4].

В рейтинг так же вошли 29 банков, включая 2 из первой десятки, с суммарным объемом реализации 6 трлн 615 млрд 765 млн руб. (табл. 4). Следует отметить, что Россельхозбанк, банк «Русский стандарт», Связь-банк, Абсолют банк и банковская группа «Зенит» при суммарном объеме реализации в 415 271,90 млн руб. заявили суммарный убыток в 85 912,70 млн руб. по результатам 2016 г.

Если сравнить объем реализации банковских услуг, которые, в общем-то, являются не «вещными» в отличие от энергетической и ресурсодобывающей отраслей, а в большей мере виртуальными, то доля объемов реализации ИТ-компаний и компаний, предоставляющих МШПД составит уже чуть более $26 \%$.

В то же время, если рассматривать процесс цифровой трансформации экономики как совокупность деятельности предприятий ИТ-сектора, услуг приема-передачи данных и услуг, предоставляемых банковским сектором (всего 8 трлн 360 млрд 599 млн руб.), то это будет даже чуть более трети (34\%) от объема реализации 10 ведущих российских предприятий ресурсодобывающей сферы и сферы естественных монополий логистики.

Компании, вошедшие в сегмент «Банковский сектор»

\begin{tabular}{|c|l|c|c|c|}
\hline $\begin{array}{c}\text { № в } \\
\text { рейтинге }\end{array}$ & \multicolumn{1}{|c|}{ Компания } & Объем реализации, млн руб. & $\begin{array}{c}\text { Прибыль до налогообло- } \\
\text { жени, млн руб. }\end{array}$ & Чистая прибыль, млн руб. \\
\hline 4 & Сбербанк России & 2835300,0 & 677500,0 & 541900,0 \\
6 & Группа ВТБ & 1217500,0 & 65500,0 & 51600,0 \\
25 & Группа «Газпромбанк» & 405121,0 & 53410,0 & 29007,0 \\
48 & Россельхозбанк & 257103,0 & $-57993,0$ & $-58926,0$ \\
49 & Группа «Альра-банк» & 255585,2 & 10453,7 & 6749,7 \\
52 & Банковская группа «ФК & 228464,0 & 2850, & 1619,0 \\
\end{tabular}


Окончание таблицы 4

\begin{tabular}{|c|c|c|c|c|}
\hline $\begin{array}{c}\text { № в } \\
\text { рейтинге }\end{array}$ & Компания & Объем реализации, млн руб. & $\begin{array}{c}\text { Прибыль до налогообло- } \\
\text { жени, млн руб. }\end{array}$ & Чистая прибыль, млн руб. \\
\hline 101 & Юникредит банк & 127398,0 & 17602,0 & 14023,0 \\
\hline 102 & Промсвязьбанк & 126948,0 & 2774,0 & 2136,0 \\
\hline 103 & Московский кредитный банк & 126792,2 & 13734,5 & 10873,6 \\
\hline 113 & Райфрфайзенбанк & 114234,8 & 29677,2 & 23285,9 \\
\hline 127 & Росбанк & 97512,0 & 4187,0 & 3104,0 \\
\hline 159 & Совкомбанк & 77398,0 & 41730,0 & 33687,0 \\
\hline 185 & Акционерный банк «Россия» & 63706,0 & 6088,6 & 4001,4 \\
\hline 193 & Хоум кредит энд фринанс банк & 60570,0 & 9716,0 & 7745,0 \\
\hline 201 & Банк «Санкт-Петербург» & 57682,3 & 5133,3 & 4277,8 \\
\hline 204 & Банк «Русский стандарт» & 57210,0 & $\begin{array}{c}-2 \text { 693,0 } \\
\text { (заявлен убыток) }\end{array}$ & $\begin{array}{c}-3210,0 \\
\text { (заявлен убыток) }\end{array}$ \\
\hline 208 & ТКС Банк & 55839,0 & 14383,0 & 11091,0 \\
\hline 237 & СМП Банк & 47079,6 & 6574,2 & 31587,2 \\
\hline 244 & Банк «Уралсиб» & 46162,3 & 3585,4 & 2030,7 \\
\hline 247 & Банковская группа «Бинбанк» & 45549,0 & 7735,0 & 3071,0 \\
\hline 257 & Ситибанк & 42549,2 & 15338,1 & 11838,0 \\
\hline 271 & «Ак Барс» & 41266,1 & 6016,8 & 5073,6 \\
\hline 296 & Связь-банк & 36230,0 & $\begin{array}{c}-8883,0 \\
\text { (заявлен убыток) }\end{array}$ & $\begin{array}{c}-8937,0 \\
\text { (заявлен убыток) }\end{array}$ \\
\hline 321 & КБ «Восточный» & 33765,3 & 4211,9 & 3198,2 \\
\hline 324 & Абсолют банк & 33234,0 & $\begin{array}{c}-2567,0 \\
\text { (заявлен убыток) }\end{array}$ & $\begin{array}{c}-2 \text { 967,0 } \\
\text { (заявлен убыток) }\end{array}$ \\
\hline 329 & $\begin{array}{l}\text { Уральский банк реконструкции } \\
\text { и развития }\end{array}$ & 32174,8 & 1708,8 & 1072,5 \\
\hline 335 & Банковская группа «Зенит» & 31494,9 & $\begin{array}{c}-12304,6 \\
\text { (заявлен убыток) }\end{array}$ & $\begin{array}{c}-11872,7 \\
\text { (заявлен убыток) }\end{array}$ \\
\hline 338 & Банк «Югра» & 31043,5 & 6478,4 & 2275,6 \\
\hline 343 & Транскапиталбанк & 30852,8 & 4607,2 & 4529,8 \\
\hline & Всего: & ррд 765 & & \\
\hline
\end{tabular}

Источник: [3]

Добыча, перемещение и распределение материальных ресурсов занимает чуть менее $2 / 3$ объема реализации в рейтинге четырехсот ведущих предприятий России. Оставшуюся 1/3 объема реализации можно отнести к деятельности, связанной с трансформацией вещной экономики в цифровую.

Таким образом, анализ приведенных данных показывает, что объем реализации восьми ведущих российских ИТ-компаний составил менее $10 \%$ от одного Газпрома. Все восемь ИТ-компаний, вошедших в рейтинг, дают только 2,2 \% объема реализации по сравнению с 8 первыми в рейтинге ресурсодобывающими компаниями. Если объединить ИТ-компании и компании по передаче мобильных данных, то их доля по сравнению с ресурсодобывающими компаниями первой десятки рейтинга составит только 7,09\% - менее $10 \%$. Если же считать, что банковские услуги составляют основную часть современной цифровой экономики наряду с ИТ-компаниями и компаниями по передаче мобильных данных, то их доля по сравнению с ресурсодобывающими компаниями первой десятки составит более трети (34\%) объема реализации, то есть на настоящий момент более трети объема реализации 400 ведущих компаний (8 трлн 360 млрд 599 млн руб.) составляют цифровые «виртуальные» товары и услуги, что позволяет говорить об уверенном процессе цифровой трансформации российской экономики. 


\section{Библиограффический список}

1. Распоряжение правительства №1632-р от 28-го июля 2017 г. Программа «Цифровая экономика Российской Федерации [Электронный ресурс]. - Режим доступа: http://static.government.ru/media/files/9gFM4FHj4PsB7 9I5v7yLVuPgu4bvR7 M0.pdf (дата обращения: 03.10.2018).

2. Указ Президента РФ от 9 мая 2017 г. № 203 «О Стратегии развития информационного общества в Российской Федерации на 2017-2030 годы» [Электронный pecypc]. - Режим доступа: http://www.kremlin.ru/acts/ bank/41919 (дата обращения: 03.10.2018).

3. Эксперт 400 [Электронный ресурс]. - Режим доступа: http://expert.ru/dossier/rating/expert-400/, свободный. Загл. с экрана. (дата обращения: 03.10.2018).

4. По прогнозу Ericsson, к 2020 г. 70 \% населения мира будет пользоваться смартфонами [Электронный ресурс]. Режим доступа: https://www.ixbt.com/ news/2015/06/06/ericsson-2020-70.html, свободный. Загл. с экрана. (дата обращения: 03.10.2018).

5. «Национальная компьютерная корпорация» (НКК) крупнейшая корпорация российского рынка информационных технологий [Электронный ресурс]. - Режим доступа: http://www.ncc.ru/, свободный. - Загл. с экрана. (дата обращения: 03.10.2018).

6. Терелянский, П. В. Цифровая экономика, искусственный интеллект, Индустрия 4.0 / П. В. Терелянский // Тенденции развития Интернет и цифровой экономики : материалы I-й всерос. с междунар. участием науч.-практ. конф. (г. Симферополь - г. Алушта, Республика Крым, 29-31 мая 2018 г.) / ФГАОУ ВО «КФУ им. В. И. Вернадского», Ин-т экономики и управления, каф. бизнес-информатики и матем. моделирования, ФГБУН ЦЭМИ РАН, ФГБОУ ВО ГУУ, ФГБОУ ВО «ОГУ им. И.С. Тургенева». - Симферополь; Алушта, 2018. - С. 91-96.

7. Апатова, Н. В. Тренды цифровой экономики / Н. В. Апатова // Тенденции развития Интернет и цифровой экономики : материалы I-й всерос. с междунар. участием науч.-практ. конф. (г. Симферополь - г. Алушта, Республика Крым, 29-31 мая 2018 г.) / ФГАОУ ВО «КФУ им. В. И. Вернадского», Ин-т экономики и управления, каф. бизнес-информатики и матем. моделирования, ФГБУН ЦЭМИ РАН, ФГБОУ ВО ГУУ, ФГБОУ ВО «ОГУ им. И.С. Тургенева». - Симферополь; Алушта, 2018. - С. 3-4.

8. Глазьев, С. Ю. Криптовалюты как новый тип денег / С. Ю. Глазьев, Р. С. Глазьев // Тенденции развития Интернет и цифровой экономики: материалы I-й всеpoc. с междунар. участием науч.-практ. конф. (г. Симферополь - г. Алушта, Республика Крым, 29-31 мая 2018 г.) / ФГАОУ ВО «КФУ им. В. И. Вернадского», Ин-т экономики и управления, каф. бизнес-информатики и матем. моделирования, ФГБУН ЦЭМИ РАН, ФГБОУ ВО ГУУ, ФГБОУ ВО «ОГУ им. И.С. Тургенева». - Симферополь; Алушта, 2018. - С. 9-20.

9. Смирнов, Е. Н. Отраслевые и функциональные аспекты развития мирового рынка систем и технологий искусственного интеллекта / Е. Н. Смирнов, П. В. Терелянский // Вестник университета (Государственный университет управления). - 2017. - № 10. - С. 30-34.

\section{References}

1. Rasporyazhenie pravitelstva № 1632-r ot 28-go iyulya 2017 g. Programma «Tsifrovaya ekonomika Rossiiskoi Federatsii [ Government decree № 1632-R of July 28, 2017 «Digital economy of the Russian Federation» Program]. Available at: http://static.government.ru/media/files/ 9gFM4FHj4PsB79I5v7yLVuPgu4bvR7M0.pdf (accessed 03.10.2018).

2. Ukaz Prezidenta RF ot 9 maya 2017 g. № 203 «O Strategii razvitiya informatsionnogo obshchestva v Rossiiskoi Federatsii na 2017-2030 godu» [The decree of the President of the Russian Federation of May 9, 2017 № 203 «On the Strategy of information society development in Russian Federation to 2017-2030»]. Available at: http://www.kremlin.ru/acts/ bank/41919 (accessed 03.10.2018).

3. Ekspert 400 [Expert 400]. Available at: http://expert.ru/ dossier/rating/expert-400/ (accessed 03.10.2018).

4. Po prognozu Ericsson, k 2020 godu $70 \%$ naseleniya mira budet pol'zovat'sya smartfonami [Ericsson predicts that by 2020, $70 \%$ of the world's population will use smartphones]. Available at: https://www.ixbt.com/news/2015/06/06/ericsson-2020-70.html (accessed 03.10.2018).

5. «Natsionalnaya komp`yuternaya korporatsiya» (NKK) krupneishaya korporatsiya rossiiskogo rynka informatsionny`kh tekhnologii [National computer Corporation (NCC) is the largest Corporation in the Russian information technology market]. Available at: http://www.ncc.ru/ (accessed 03.10.2018).

6. Terelyanskiy, P. V. Tsifrovaya ekonomika, iskusstvennyi intellekt, Industriya 4.0 [The Digital economy, artificial intelligence, Industry 4.0] / Tendentsii razvitiya Internet i tsifrovoi ekonomiki : materialy` I-i vseros. s mezhdunar. uchastiem nauch.-prakt. konf. (g. Simferopol - g. Alushta, Respublika Krym, 29-31 maya 2018 g.) [Trends in the development of the Internet and the digital economy: materials of the I-th all-Russia with international participation sci.-practical. conf. (Simferopol - Alushta, Republic of Crimea, from 29 to 31 May 2018)] / FGAOU VO «KFU im. V.I. Vernadskogo», In-t ekonomiki i upravleniya, kaf. biznes-informatiki i matem. modelirovaniya, FGBUN CzE'MI RAN, FGBOU VO GUU, FGBOU VO «OGU im. I.S. Turgeneva» [FSAEI HE «Kazan Federal University Vernadsky's name», Institute of Economics and Management, dept. Business Informatics and Math. modeling, Institute of Central Economics and Mathematics Institute Russian Academy of Sciences, FSBEI HE «OSU I. S. Turgenev's name»]. Simferopol; Crimea, Alushta, 2018, pp. 91-96.

7. Apatova, N. In. Trendy` tsifrovoi ekonomiki [The trends of the digital economy] / Tendentsii razvitiya Internet i tsifrovoi ekonomiki: materialy I-i vseros. s mezhdunar. uchastiem nauch.-prakt. konf. (g. Simferopol - g. Alushta, Respublika Krym, 29-31 maya 2018 g.) [Tendencies of development of the Internet and the digital economy: materials of the I-th all-Russia. with international. participation of scientists. prakt. Conf. (Simferopol - Alushta, Republic of Crimea, from 29 to 31 May 2018)] / FGAOU VO «KFU im. V. I. Vernadskogo», In-t e konomiki i upravleniya, kaf. biznes-informatiki i matem. modelirovaniya, FGBUN CzE'MI RAN, FGBOU VO GUU, FGBOU VO «OGU im. I.S. Turgeneva» [FSAEI $H E$ «Kazan Federal University Vernadsky's name», Institute of Economics and Management, dept. Business Informatics and Math. modeling, Institute of Central Economics and Mathematics Institute Russian Academy of Sciences, FSBEI HE «OSU I. S. Turgenev's name»]. Simferopol; Crimea, Alushta, 2018. Pp. 3-4. 
10. Костикова, А. В. Комплексная методика исследования социально-экономических показателей региона на базе интеграции субъективных и объективных данных / А. В. Костикова, И. Е. Егорова, П. В. Терелянский // Известия ВолгГТУ. Сер. Актуальные проблемы реформирования российской экономики (теория, практика, перспектива). - Волгоград, 2016. - № 1 (180). - C. 156-166.
8. Glaziev, S. Y. Kriptovalyuty' kak novyi tip deneg [Cryptocurrency as a new type of money] / Tendentsii razvitiya Internet i tsifrovoi ekonomiki : materialy` I-i vseros. s mezhdunar. uchastiem nauch.-prakt. konf. (g. Simferopol - g. Alushta, Respublika Krym, 29-31 maya 2018 g.) [Trends in the development of the Internet and the digital economy : materials of the I-th all-Russia. with international. participation of scientists.- prakt. Conf. (Simferopol - Alushta, Republic of Crimea, from 29 to 31 may 2018)] / FGAOU VO «KFU im. V. I. Vernadskogo», In-t ekonomiki i upravleniya, kaf. biznes-informatiki i matem. modelirovaniya, FGBUN CzE`MI RAN, FGBOU VO GUU, FGBOU VO «OGU im. I.S. Turgeneva» [FSAEI HE "Kazan Federal University Vernadsky's name», Institute of Economics and Management, dept. Business Informatics and Math. modeling, Institute of Central Economics and Mathematics Institute Russian Academy of Sciences, FSBEI $H E$ «OSU I. S. Turgenev's name»]. Simferopol; Crimea, Alushta, 2018-Simferopol; Crimea, Alushta, 2018, pp. 9-20.

9. Smirnov, E. N. Otraslevye i funktsional nye aspekty razvitiya mirovogo rynka sistem i tekhnologii iskusstvennogo intellekta [Branch and functional aspects of development of the world market of systems and technologies of artificial intelligence]. Vestnik universiteta (Gosudarstvennyi universitet upravleniya), 2017, I. 10, pp. 30-34.

10. Kostikova, A. V. Kompleksnaya metodika issledovaniya sotsial'no-ekonomicheskikh pokazatelei regiona na baze integratsii sub"ektivnykh i ob"ektivnykh dannykh [Complex methods of research of socio-economic performance of the region based on the integration of subjective and objective data]. Izvestiya VolgGTU. Ser. Aktual'nye problemy reformirovaniya rossiiskoi ekonomiki (teoriya, praktika, perspektiva) [Izvestia VSTU. Series Actual problems of reforming the Russian economy (theory, practice, perspective)]. Volgograd, 2016, I. 1(180), pp. 156-166. 